\title{
Prevention and Control of
}

\section{Healthcare-Associated with Infections in Birth Rooms of Referral Hospitals in Ouagadougou: Availability of Equipment, Knowledge and Practices of Health Workers}

\author{
Der Adolphe Some1, P. Aline Tougma², Souleymane Ouattara1, Caroline Yonaba Okenge3, \\ Gandaaza Armel E. Poda1, R. Barnabé Yameogo1, Semon Paulin Kam1, Bintou Traore1, \\ Sansan Rodrigue Sib4, Blandine Thieba Bonane ${ }^{3}$, Blami Dao5 \\ ${ }^{1}$ Souro Sanou University Teaching Hospital, Bobo-Dioulasso, Burkina Faso \\ ${ }^{2}$ University Hospital Teaching of Bogodogo, Ouagadougou, Burkina Faso \\ ${ }^{3}$ Yalgado Ouédraogo University Teaching Hospital, Ouagadougou, Burkina Faso \\ ${ }^{4}$ Regional University Teaching Hospital of Ouahigouya, Ouahigouya, Burkina Faso \\ ${ }^{5}$ Jhpiégo, Ouagadougou, Burkina Faso \\ Email: adolphesomeder@yahoo.fr
}

How to cite this paper: Some, D.A., Tougma, P.A., Ouattara, S., Yonaba Okenge, C., Poda, G.A.E., Yameogo, R.B., Kam, S.P., Traore, B., Sib, S.R., Thieba Bonane, B. and Dao, B. (2020) Prevention and Control of Healthcare-Associated with Infections in Birth Rooms of Referral Hospitals in Ouagadougou: Availability of Equipment, Knowledge and Practices of Health Workers. Open Journal of Obstetrics and Gynecology, 10, 135-150.

https://doi.org/10.4236/ojog.2020.1010012

Received: November 25, 2019

Accepted: January 10, 2020

Published: January 13, 2020

Copyright $\odot 2020$ by author(s) and Scientific Research Publishing Inc. This work is licensed under the Creative Commons Attribution International License (CC BY 4.0).

http://creativecommons.org/licenses/by/4.0/

\begin{abstract}
Objective: The neonatal mortality rate remains a serious problem in most countries in sub-Saharan Africa such as Burkina Faso, where, in 2010 this mortality rate was 28 per 1000 live births [1] [2]. Its reduction is possible and passes first by the strict prevention of infections in birth rooms. The objective of this study was to describe the practices of infection prevention in the birth rooms of seven referral hospitals in Ouagadougou from April 1 to July 31, 2016. Materials and Methods: This was a cross-sectional study on the knowledge, attitudes and practices of the rules of prevention and control of healthcare associated infections (PCHAI) among 123 consenting health workers who provided birth room care in 7 hospitals in Ouagadougou. Data were collected through individual interviews and direct observations. The study was authorized by the Institutional Ethics Committee in 2015 under the number 32. The data analysis was done with the Epi Info software version 2000. Results: The "five clean in the birth room" were known by $26.83 \%$. Regarding the equipment used for PCHAI, sterile gloves were mentioned by $75.61 \%$ of the agents, the source of clean water by $62.60 \%$ and soap by $57.11 \%$; in practice, $17.07 \%$ of the respondents had not washed their hands and 42 providers (34\%) had not performed with complete mastery the wear-
\end{abstract}


ing of sterile gloves before giving birth, and 55.28\% had not cleaned the perineum. Conclusion: Deficiencies in the prevention and control of healthcare-associated infections have been identified. Training on infection prevention in the neonatal period is needed for the benefit of hospital providers.

\section{Keywords}

Newborn Cares, Infection Prevention, Knowledge, Practice, Ouagadougou

\section{Introduction}

The determinants of neonatal mortality are known. They are multifactorial and classified into three groups. The group of direct causes includes medical pathologies, mainly severe infections (38\%) such as pneumopathy/septicemia (28\%); tetanus $(6 \%)$ and diarrhea (4\%). In the second group of indirect causes, there is prematurity (25\%), asphyxia (24\%) and congenital malformations (6\%) [3]. But at the center of all these pathologies is low birth weight, which is the third leading cause of neonatal death [4].

PCHAI rules during childbirth or newborn care are a possible determinant of neonatal death if these rules are not known and followed.

The actions carried out have enabled Burkina Faso to be ranked among the six (06) low-income countries that have succeeded in significantly reducing the neonatal death rate. Nevertheless, sub-Saharan Africa remains the most dangerous region in the world for an unborn child [5]. However, the rules for effectively preventing infections in the birth room are simple. These include above all the use of protective measures and respect for "the five clean". This cleanliness concerns 1) the hands, 2) the surfaces and linens, 3) the scissors and blades, 4) the ligation of the cord and 5) the condition of the cord until it is scarred. The purpose of this study was to learn about the practices of health workers in Ouagadougou's referral hospitals regarding neonatal PCHAI in order to propose corrective measures.

\section{Materials and Methods}

\subsection{Type, Period and Location of the Study}

This was a cross-sectional study with prospective data collection from September 2015 to July 2016. It took place in the maternity wards of 7 reference hospitals in the city of Ouagadougou, namely Yalgado Ouédraogo Hospital, Saint Camille Hospital, medical centers with surgical antenna (MCSA) of Kossodo, Bogodogo, Pissy, Paul VI and Shiphra.

\subsection{Study Population}

\section{- Inclusion criteria}

The study aimed agents of health centers who were regularly involved in 
childbirth and the immediate essential care of newborns (IECN). Only those who were present at the time of the study and gave their free and informed written consent to be interviewed and observed were included.

\section{- Criteria of non-inclusion}

Trainees and other non-permanent health workers at the time of the study were not included.

\section{- Sample and sampling}

Agents were randomly and systematically included. In fact, during the three months outings for investigations, agents who were on duty were informed of the study and then invited to participate by signing freely the informed consent form. A total of 151 of them were expected.

\subsection{Methods, Techniques and Instruments}

The data were collected through direct semi-structured individual interviews using a written questionnaire that was validated by a pre-test. In addition, three direct participatory observations were made by agents using a grid established for this purpose. The verification of infection prevention equipment in each department was done by referring to existing lists.

\subsection{The Variables Sought}

During the interviews, the socio-demographic and professional characteristics of the providers, the providers' knowledge of infection prevention equipment and consumables and their knowledge of infection prevention rules were sought.

When officers were observed, their practices were assessed using scores. The scores were derived from the benchmark for the ideal practice of essential newborn care, the reference manual on newborn care [5]. The zero (0) score meant that the provider had not performed the act; the one (1) meant that the act was incorrectly performed; the 2 score was given when the act was performed without control; the 3 for the act well performed with good control and the 4 score for the act very well performed with perfect control.

With regard to equipment and medicines, the tasks were distributed as follows: a first investigator was responsible for checking the equipment in the delivery room and operating room and then for contacting the person in charge of the delivery room to find out how the service was organized; the second investigator was responsible for checking the medicines in the pharmacy.

\subsection{Investigators and Supervisor}

The survey was conducted by 14 resident physicians in obstetrics and gynaecology and midwives; they were trained in collection techniques and ethics and confidentiality for 2 days. Two investigators were assigned to each hospital. They divided up the duty and duty teams to be investigated, and then returned to hospitals according to the teams' schedule. Thus, the person who had observed a claimant once would see him again the other two times. He administered the 
questionnaire to that health worker after the third and final observation. Throughout the data collection, these interviewers were supervised for data quality assurance.

\subsection{Ethical Considerations}

Authorization number 32 of October 31, 2015 from the Institutional Ethics Committee of Muraz Centre, as well as administrative authorizations from the hospital directorates to conduct the study, have been obtained. All study participants had freely signed the informed consent form. The anonymity and confidentiality of the content of the questionnaires were guaranteed throughout the study.

\subsection{Data Analysis}

The data were analyzed with the Epi Info software version 2000.

\section{Results}

The final sample consisted of 123 providers out of the 151 initially expected, representing a participation rate of $81.45 \%$.

\subsection{Population Characteristics}

The health workers were between 30 and 39 years old, had been working as qualif at least one year, and had studied until secondary school. Most of them were from the Medical center with surgical antenna (MCSA) of KOSSODO. In Table 1 are presented the socio-professional characteristics of the respondents.

Table 1. Distribution of the sample according to socioprofessional characteristics.

\begin{tabular}{lll}
\hline Socioprofessional characteristics & Effectif & Proportion (\%) \\
\hline Age (years) & 12 & 10 \\
$\leq 29$ & 72 & 58.53 \\
$30-39$ & 29 & 23.57 \\
$40-49$ & 10 & 7.90 \\
$\geq 50$ & & 5.7 \\
Level of schooling & 7 & 15.4 \\
Primary & 19 & 78.9 \\
Secondary & 97 & 13.0 \\
University & 18 & \\
Medical center & & 16.3 \\
YalgadoOuédraogo university & 20 & \\
Teaching Hospital & & \\
Medical center with surgical & & \\
Antenna (MCSA) of sector 30 & 16 & \\
Schiphra MCSA & & \\
\hline
\end{tabular}




\begin{tabular}{lcc} 
Continued & & \\
\hline Saint Camille Hospital & 13 & 10.6 \\
MCSA of Pissy & 19 & 10.5 \\
MCSA Paul VI & 13 & 19.5 \\
MCSA of Kossodo & 24 & \\
Qualification & 113 & 92.0 \\
Midwife & 10 & 8.0 \\
Auxiliary midwife & & \\
Seniority in this qualification (ans) & 17 & 14.0 \\
$<1$ & 68 & 55.3 \\
$1-5$ & 28 & 22.7 \\
6 - 10 & 10 & 8.0 \\
$>10$ & & \\
\hline
\end{tabular}

\subsection{Training Received on Newborn Care}

All providers (100\%) had received basic training in essential newborn care and $42 \%$ had subsequently received additional training, including emergency obstetric and neonatal care (24\%), neonatal resuscitation (11\%) and essential newborn care (4\%). None had received training in the prevention and control of healthcare-associated infections.

\subsection{Infection Control Equipment and Consumables}

\section{Detergents and disinfectants}

Liquid soap and chlorinated water were available in all maternity wards. The hydro-alcoholic solution was available in two of the seven maternity hospitals, or $28.57 \%$ of the cases.

\section{Sterile equipment and consumables}

The sterile scissors, Baar clamps and clamps were available in the seven reference maternity units. Scalpels and sterile fields were present in $57.14 \%$ and $42.86 \%$ of cases respectively.

\section{Material for the protection barrier}

Coats, bibs, caps and hooves were available in all maternity hospitals, except for safety glasses.

\section{High level sterilization or disinfection equipment}

A nursery was present in six maternity wards, representing $85.71 \%$ of cases, and an autoclave in four, representing $57.14 \%$ of cases. High level disinfection equipment existed in $28.57 \%$ of cases.

Other materials and consumables used for infection prevention

Running water, sharp boxes and garbage cans were available in all maternity hospitals.

Hand towels were available in 3 maternity wards or $42.86 \%$. Collective towels 
were used in one maternity ward or $14.29 \%$ and individual towels in two maternity ward or $28.57 \%$ of cases.

\subsection{Knowledge of the Principles of Infection Control in the Neonatal Period}

\section{Knowledge of the "five clean"}

Among the 123 providers, 33(26.83\%) knew at least one component of the "five clean". The level of knowledge of these providers on the component of the "five clean" is reported in Table 2.

The average level of knowledge of the components of the five clean ranged from $15.45 \%$ for "clean and dry cord until it heals" to $26.06 \%$ for "clean hands" and "clean surfaces and linens".

\section{Means used for hand hygiene}

Handwashing was cited by 115 providers (93.50\%) and friction with a hydro-alcoholic solution, by 68 service providers (55.28\%).

\section{Competency check on infection control}

The level of competence of providers in infection prevention is noted in Table 3.

The protection barrier had been used by all providers. Of these, 59 had used it without control. The maternal perineum had been cleaned, before the birth of the newborn by 55 providers, three of them had performed it with perfect control.

Table 2. Frequency of responses on the components of the "five clean" $(n=123)$.

\begin{tabular}{lll}
\hline Components of the five clean & Frequency & Proportion (\%) \\
\hline Hands clean & 32 & 26.02 \\
Clean surfaces and linens & 32 & 26.02 \\
Clean scissors and blades & 25 & 20.33 \\
Clean cord ligatures & 23 & 18.7 \\
Clean and dry cord until it heals & 19 & 15.45
\end{tabular}

Table 3. Distribution of providers' competence elements on infection control according to the quality of their execution $(n=123)$.

\begin{tabular}{llllllll}
\hline \multicolumn{7}{l}{ Quality of execution of the competence } \\
\hline Infection Control Element & $\begin{array}{l}\text { Not } \\
\text { executed }\end{array}$ & $\begin{array}{l}\text { Poorly } \\
\text { executed }\end{array}$ & $\begin{array}{l}\text { Without } \\
\text { control }\end{array}$ & $\begin{array}{l}\text { Good } \\
\text { control }\end{array}$ & $\begin{array}{l}\text { Perfect } \\
\text { control }\end{array}$ & $\begin{array}{l}\text { Total } \\
\text { executed }\end{array}$ \\
\hline Hand washing & 21 & 14 & 28 & 34 & 26 & 102 \\
Protection barrier & 0 & 4 & 59 & 53 & 7 & 123 \\
Wearing sterile gloves & 2 & 3 & 26 & 50 & 42 & 121 \\
Cleaning the perineum & 68 & 24 & 14 & 14 & 3 & 55 \\
Decontamination of equipment & 4 & 4 & 60 & 21 & 34 & 119 \\
\hline
\end{tabular}




\section{Discussion}

Health workers receive continuous training once they have left training institutions. We note that none of the providers surveyed had received additional training in prevention and control of healthcare associated infections (PCHAI); however, these additional training sessions are necessary for upgrading and acquiring new skills. Tonleu in his study found that more than half of the providers did not remember an upgrading course [6]. The training of a sufficient number of qualified providers must be based on the coordination of management policies, human resources in order to ensure equitable distribution and quality care [7].

Basic care must respect the infection prevention rules that recommend soap and chlorine solution in all maternity wards [8]. But the hydro-alcoholic solution existed in only $28.57 \%$ of the maternity hospitals in our study. It is a non-irritating alcohol-based solution to which glycerin is added; it works effectively to prevent infections [9]. To compensate for this deficiency, it is desirable that each maternity hospital produces its own hydro-alcoholic solution. It is easy to do and should not be missed in a maternity ward.

Also in the context of PCHAI, sterile equipment is essential in the birth room to ensure asepsis during delivery. In our study, sterile scissors and pliers were found in all maternity hospitals. However, scalpels and sterile fields existed but they were not in sufficient quantity [8]. The lack of autoclaves in some reference maternity hospitals would explain this absence of sterile fields. Scalpels were also temporarily unavailable in some formations. This suggests a simple stock management problem!

As for the equipment for the protection barrier, it is the first means used in infection prevention. It is accepted that the wearing of gown, clogs, cap, and bib is mandatory in the delivery room [8]. During our survey, all maternity hospitals had this equipment. However, protective glasses or visors were not available. This could be due to lack of resources or visual discomfort when some health workers wear protective eyewear.

Sterilization of equipment as the most effective means of infection prevention must be a priority for any surgical facility [9]. Indeed, not all maternity hospitals had an autoclave and high level disinfection (HLD) equipment. At the national level, an evaluation conducted as part of the implementation of emergency obstetric and neonatal care revealed that $87 \%$ of babies existed in the reference maternity units [8]. This would be explained by its more affordable cost. With the exception of the poupinel, high-level sterilization or disinfection equipment is lacking in the reference maternity hospitals in the city of Ouagadougou. However, the baby doll is no longer recommended for effective sterilization. Instead, steam sterilization, using an autoclave [10], should be preferred. The latter allows the sterilization of a greater number of materials, compared to the poupinel [9]. It would therefore be more appropriate for all reference maternity hospitals to purchase them. 
Other materials and consumables are used for infection prevention such as running water, cutting edge boxes and garbage cans, which were available in all the reference maternity hospitals in the city of Ouagadougou. In most publications, the findings were similar [6] [8] [11]. The use of hand towels, collective and individual towels is low. Nennig in France in 2009, in her study on cord care, found that paper towels were used to dry hands by caregivers in $89 \%$ of cases [12]. The collective cloth towel is to be avoided, as it can be a source of cross-infection. Indeed, a hand towel, in a hospital setting, should only be used once, in order to avoid transmission to users [13]. In addition to the hand towel, it is recommended to dry your hands outdoors. Most of these measures are simple to apply to prevent infections, which are the cause of neonatal death in $38 \%$ of cases [2].

In terms of infection prevention, hand hygiene is a quality indicator, highlighting the safety of health care systems [14]. Hand washing was known to providers as a way to make hands clean. But friction with a hydro-alcoholic solution was cited only in $55.28 \%$ of cases. This result is explained by the non-existence of this product in the reference maternity hospitals.

Knowledge of the five own and their components is insufficient. It is true that this is a new concept, but this inadequacy is confirmed by the high neonatal mortality rate linked to infections of $32 \%$ [15]. It is therefore necessary to regularly update the knowledge and practices of providers.

While in our study, the level of competence for infection prevention appears to be good, on the other hand, few providers had performed the procedures with perfect control. Indeed, more than half of the sample performed gestures to prevent infections in the birth room; but only half among them executed gestures satisfactorily. This analysis suggests that level of infection prevention practices is average among agents who apply it. The lack of equipment and insufficient knowledge could explain this poor execution of prevention measures. This is one of the reasons why infections remain at the forefront. It is appropriate for providers' practices to change. The objective of the training must be based on social and behavioral change, because the agents work routinely and are therefore no longer effective.

\section{Limits}

The limits of this study could be related on the one hand, to the duration of three months for the investigation; this delay did not allow enlisting all the providers since some of them were on leave. On the other hand, the presence of the interviewer may have sometimes influenced the behavior and the responses of the providers. But the results obtained are interesting and have been discussed, commented and compared to the data of the literature.

\section{Conclusion}

Equipment and materials for infection prevention in the neonatal period remain 
insufficient in the reference maternity hospitals in the city of Ouagadougou. As for the knowledge and skills of health care providers, efforts must be focused on continuous behavior change and training to ensure safe neonatal care.

\section{Conflicts of Interest}

The authors declare no conflicts of interest regarding the publication of this paper.

\section{References}

[1] INSD, DHS and ICF (2010) Burkina Faso. Enquête démographique et de santé et indicateurs multiples du Burkina Faso. INSD et ICF International, Merrylands.

[2] Republique du Senegal, Ministere de la Prevention (2008) Guide du formateur des prestataires. Soins essentiels du nouveau-né Sénégal. 36-37, 65 p.

[3] OMS (2011) Analyse de la situation sanitaire dans la région africaine. Ed: Bureau régional de l'OMS pour l'Afrique, $42-45,104 \mathrm{p}$.

[4] OMS (2006) Une chance pour les nouveau-nés d'Afrique. http://www.who.int/mediacentre/news/releases/2006/pr70/fr

[5] Beck, D., Ganges, F., Goldman, S. and Long, P. (2003) Manuel de référence des soins aux nouveau-nés. Save the Children Federation, Westport, 6-54, 238 p.

[6] Tonleu, E.C. (2014) Evaluation de la qualité des soins essentiels offerts aux nouveau-nés dans les maternités des centres médicaux de la ville de Ouagadougou Thèse méd. Université Saint Thomas D’Aquin, Ouagadougou, Burkina Faso, 58-60, 75-78, $121 \mathrm{p}$.

[7] Jhpiego Corporation (2012) Guide de mise en œuvre de programme des soins essentiels et néonatals essentiels (SONE). Corporation Jhpeigo, Baltimore, 7-8, 14 p.

[8] Ministere de la Recherche Scientifique et de l'innovation du Burkina Faso (2010) Evaluation des besoins en soins obstétricaux et néonataux d'urgence, couplée à la cartographie de l'offre de soins en santé de la reproduction au Burkina Faso. 119-120, 125-136, $339 \mathrm{p}$.

[9] Tietjen, L., Cronin, W. and Mcintosh, N. (1992) Prévention des infections Guide pratique à l'intention des programmes de planification familiale. International Planned Parenthood Federation, London, 3-2, 6-2, 218 p.

[10] Dupuy, C. (2018) Approche globale de la validation de la stérilisation par autoclavage: Optimisation et choix stratégiques. Thèse Pharm. No. 33, Université de Bordeaux, 103 p. https://dumas.ccsd.cnrs.fr/dumas-01803679/documen

[11] Sanou, F. (2004) Prise en charge des nouveau-nés en salle de naissance dans les maternités de la ville de Ouagadougou. Thèse méd., Université Ouaga I Joseph Ki-Zerbo, Ouagadougou, Burkina Faso, 49-53, 97 p.

[12] Nennig, L. (2009) Etude sur le soin du cordon ombilical dans les maternités de Lorraine. Thèse pharm, Université Henri Poincare, Nancy, 143-144, 224 p.

[13] France Ministere de la Sante, de la Famille et des Personnes Handicapees, Direction Generale de la Sante (2002) Guide de bonnes pratiques pour la prévention des infections liées aux soins réalisées en dehors des établissements de santé. 49, $140 \mathrm{p}$.

[14] Boiro, D. (2016) Evaluation des connaissances sur les soins essentiels du nouveau-né (SENN) et la prévention des infections chez le personnel de sante en maternité à DAKAR. Revue du CAMES: Science de la Santé, 4, 63-67 http://publication.lecames.org/index.php/sante/article/view/937

[15] Ministere de la Sante Burkina Faso (2011) Plan national de développement sanitaire 2011-2020. 4-5, $56 \mathrm{p}$. 


\section{Appendix: Data Collection Form}

\section{I) IDENTIFICATION}

1) Identification number:

2) Date of the survey

3) Surname and first name of the investigator

4) Surname and First name of the service provider.

5) The past age of the service provider

6) Provider's educational level.

7) Marital status of the provider

8) Current qualification of the service provider

9) Residence of the service provider.

10) Service provider's seniority in the service.

11) Training received by the provider on newborn care.

12) Health facility of origin:

$\square$ YalgadoOuédraogo UTH

Medical Center with surgical antenna (MCSA) or Sector 30

Schiphra MCSA

Saint Camille Hospital

MCSA of PISSY

MCSA of Paul VI

MCSA of Kossodo

II) VERIFICATION GRID OF CONDITIONS OF WORK

Health facility:

Date of the survey:
A) Basic newborn care equipment
1) Two clean and dry cloths
2) Cap
3) Slippers
4) Antiseptic or antibiotic eye drops
5) Antiseptic for umbilical care (Chlorhexidine)
6) Barr Clamp or clean wire for ligature
7) Sterile compresses
8) Vitamin $\mathrm{k}$
9) Centimeter-flexible
10) Baby scale
11) Identification bracelet
B) Infection prevention equipment and consumables
1) Water Source/Clean Water
2) Liquid soap
3) Solid soap
4) Hand towels
5) Individual clean towel
6) Collective towel 
7) Hydro-alcoholic solution

8) Bleach/chlorine solution

9) Waste bin

10) Edge box

11) Calot

12) $\mathrm{Bib}$

13) Dedicated service shoes

14) Autoclave

15) Poupinel

16) HLD

17) Sterile fields

18) Sterile scissors

19) Sterile pliers

20) Scalpel blades

C) Infection management and availability of antibiotics

1) Ampicillin

2) Penicillin $G$

3) Amoxicillin

4) Oxacillin

5) Ciprofloxacin

6) Gentamicin

7) ARV

D) Other drugs and equipment for the care of the newborn

1) $5 \%$ Glucose serum

2) Glucose serum $10 \%$

3) Isotonic saline serum

4) Ringer's lactate

5) Calcium Gluconate

6) Calcium chloride

7) Adrenaline

8) Vitamin $K$

9) Venous catheter for newborns

10) Umbilical hinged catheter 5

11) Umbilical hinged catheter 3.5

E) Hypothermia management

1) Table with heating lamp industrial model

2) Table with heating lamp handcrafted model

3) Kangaroo care unit

4) Kangaroo care practice

5) Heating mattress

6) Livestock incubator

F) Feeding the at-risk newborn

1) Electric milk puller 
2) Mechanical milk puller

3) Manual milk extraction

4) Mug for feeding

5) Refrigerator for preserving expressed milk

6) Gastric probe

7) Feeding syringe

G) Management of asphyxia

1) Asphyxiated newborn care area in the delivery room

2) Management area for asphyxiated newborn babies in the obstetrical operating room

3) Wall oxygen source

4) Oxygen extractor

5) Electric mucus suction device

6) Mechanical mucus suction device

7) Suction bulb

8) Suction probe $N^{\circ} 6$

9) Suction probe $N^{\circ} 8$

10) Suction probe $N^{\circ} 10$

11) Ventilation bag for newborns

12) Ventilation mask $N^{\circ} 0$

13) Ventilation mask $N^{\circ} 1$

14) Laryngoscope

15) Stopwatch

16) Stethoscope

17) Glucometer

18) Portable satsometer

19) Resuscitation protocol sheet

H) Transfer of newborns

1) Transport incubator

2) Medical Ambulance

3) Ambulance not equipped

4) Adapted transfer form

5) Transfer form not adapted

6) Telephone for communication

I) Hospitalization of newborns
1) Newborn hospital room
2) Newborn hospital record
3) Computerized support of medical records
4) Consultation register for newborns
5) Hospitalization register for newborns
J) Organization of personnel
1) Number of service providers
2) Organizational chart table 


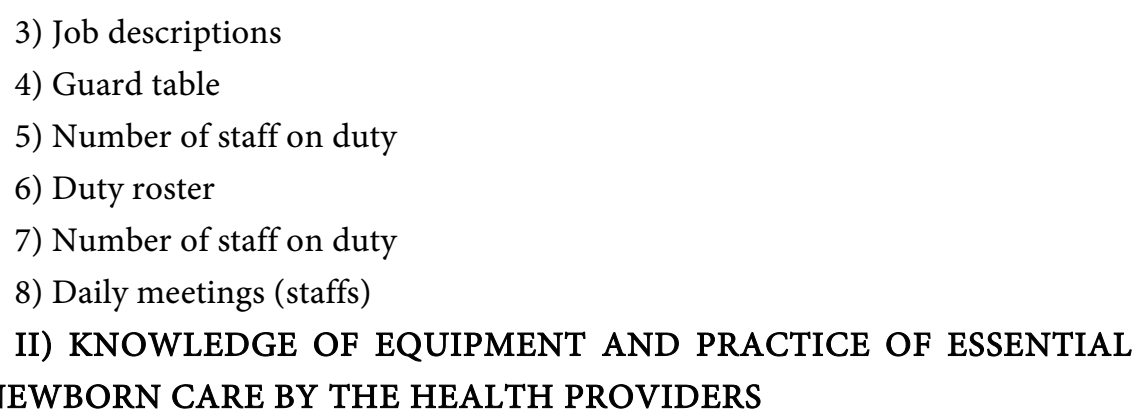

\section{A) Knowledge of care equipment}

A1: What is the equipment used for basic immediate care of newborns?

1) Two clean and dry cloths

2) Cap

3) Slippers

4) Antiseptic or antibiotic eye drops

5) Antiseptic for umbilical care (Chlorhexidine)

6) Barr Clamp or clean wire for ligature

7) Sterile compresses

8) Vitamin K1

9) Centimeter-flexible

10) Baby scale

11) Identification bracelet

A2: What is the equipment used to prevent infection in the neonatal period?

1) Clean water source

2) Liquid soap or solid soap (if not available)

3) Clean towel or hand towel

4) Clean gloves

5) Sterile scissors

6) Sterile scalpels

A3: What is the equipment used for the resuscitation of the newborn at birth?
1) Industrial or artisanal heating table
2) Two clean and dry linens
3) Mucus suction device
4) Pear
5) Suction probe $N^{\circ} 6$
6) Suction probe $\mathrm{N}^{\circ} 8$
7) Suction probe $N^{\circ} 10$
8) Ventilation bag for newborn babies
9) Ventilation mask $\mathrm{N}^{\circ} 0$
10) Ventilation mask $N^{\circ} 1$
11) Stopwatch
12) Stethoscope 


\section{B) Knowledge of the organization of care}

Can you briefly describe how the care of the newborn at birth is organised in a reference maternity hospital?

1) Setting up a newborn corner

2) Component of a corner of the newborn: resuscitation table with heated lamp - mucous suction device - ventilation bag

3) Newborn corner in the delivery room

4) Newborn corner in the operating room

5) Newborn corner in neonatology department

6) Organization of joint meetings between obstetricians and paediatricians

7) Development of common protocols between obstetricians and paediatricians

8) Organize perinatal management of high-risk pregnancies in consultation with others

C) Knowledge of care procedures

C1: Can you describe the basic immediate care procedures for the newborn at birth?

1) Dry and stimulate the newborn

2) Assess the newborn (screaming and breathing)

3) Putting skin to skin

4) Carry out cord care (sectioning and application of antiseptic)

5) Early initiation of breastfeeding (within one hour of birth)

6) Administer eye drops in the eyes

7) Administer vitamin K1

8) Identify the newborn with an armband

9) Register the newborn baby

10) Examine the newborn baby

11) Give advice to parents

C2: Can you outline the principles of infection control

12) Knowledge of the five propres (do you know the 5 propres? yes or no answers)

13) Name the 5 clean ones

1- clean hands

2- clean surfaces and linens

3- scissors and clean blades for the cord

4- clean ligation of the cord

5- clean and dry cord until it heals

14) Means used to make hands clean

- hand washing

- friction with a hydro-alcoholic solution

III) INSTRUCTIONS FOR THE EVALUATION OF SERVICE PROVIDERS

1) Explain to the service provider how the evaluation is done

2) Observe the service provider without intervening while he is performing the different tasks. 
3) Only intervene if the service provider is committing serious misconduct

4) The numbers mean:

$0=$ the service provider did not perform the procedure

$1=$ the gesture is incorrectly executed

$2=$ the gesture is executed without control

$3=$ the gesture is well executed with good control

$4=$ the gesture is very well executed with perfect control

5) Record the provider's points and evaluate the score in percentage terms

6) Communicate to the service provider his performance, encourage him and reassure him on the confidentiality of the data

\section{COMPETENCE CHECKING GRID Date}

\begin{tabular}{ccccc}
\hline Surname and first name(s): & \multicolumn{3}{c}{ Number: } \\
\hline TASKS & 0 & 1 & 2 & 3 \\
\hline
\end{tabular}

\section{INFECTION PREVENTION}

1 Welcome the woman with respect

2 Explain to the woman the reason for the investigator's presence

3 Wash hands thoroughly with an antiseptic or soap and running water

4 Wear a clean gown, hat, bib, apron, hooves, glasses

5 Wear sterile gloves for delivery and to examine the newborn

6 Clean the perineum with an antiseptic before expelling the fetus

$$
\text { Decontaminate used equipment and gloves with chlorinated water after delivery and }
$$
examination of the newborn

\section{IMMEDIATE CARE FOR THE NEWBORN}

Immediately dry the body and head of the newborn immediately

Check that the newborn is breathing normally

Start resuscitation when the newborn is not breathing normally

Wrap it in a clean, dry cloth and cover the newborn's head as well

Ensure skin-to-skin contact with mother

Ensure that the newborn's bath is delayed for at least 12 hours

Attach clamps or tie knots to the cord

Cut the cord between the knots or the Barr clamp and the clamp

Cut the cord with sterile scissors

Do not apply anything to the bead stump

Leave the cord free

Communicate with the mother about breastfeeding and danger signs

Encourage the mother to breastfeed the newborn

Helping the mother to put the newborn to the breast

Teach the mother the correct feeding technique

Do not interrupt the feeding 
D. A. Some et al.

\section{Continued}

\section{SUBSEQUENT CARE AND PRECAUTIONS}

24 Measure the anthropometric parameters of the newborn child

25 Carefully examine the newborn for malformations

26 Administer antibiotic eye drops to the newborn

27 Giving vitamin $\mathrm{K} 1$ to the newborn

28 Give advice to the mother

29 Include the newborn's data in the health record and/or medical file

30 Complete the rest of the information on the health record and/or medical file 